\title{
Comparison of Single, Binary and Temperature- Dependent Adsorption Models Based on Error Function Analysis
}

\author{
John Fianu, Jebraeel Gholinezhad, Mohamad Hassan \\ School of Energy and Electronic Engineering (SENE), University of Portsmouth, POI 3DJ, Portsmouth, UK
}

Correspondence: Jebraeel Gholinezhad, School of Energy and Electronic Engineering (SENE), University of Portsmouth, POI 3DJ, Portsmouth, UK, Email jebraeel.gholinezhad@port.ac.uk

Received: February II, 2019 | Published: April 23, 2019

Copyright@ 2019 Fianu et al. This is an open access article distributed under the terms of the Creative Commons Attribution License, which permits unrestricted use, distribution, and reproduction in any medium, provided the original author and source are credited.

\begin{abstract} in both coal/shale gas reservoirs.

Introduction

Shale gas reservoirs are characterised by gas adsorption on shale matrix and free gas stored within the pores of the matrix. Both free gas and adsorbed gas make up a large portion of the total gas in place of these reservoirs, with gas adsorption estimated to be about $20-85 \%$ of the total gas in place. ${ }^{1}$ Gas adsorption plays an important role in the estimations of the overall gas in place which, in turn, is crucial when developing these resources for future production. Over the years, Langmuir isotherm has remained one of the most popular models used in representing the relationship between the amount of gas adsorbed and pressure. However, several other models have also been developed that can comparatively represent the adsorption process in most of these shale reservoirs. ${ }^{2-10}$ To ensure accurate representation of the amount of gas adsorbed, these models need to be evaluated and compared with the experimental data for the gas adsorption in the shale matrix. Since each shale rock might show unique properties, it may not be possible to select a single model to represent the adsorption process in all the shale formations. For instance, it has been reported that Brunauer, Emmet and Teller (BET) model represents the adsorption process in Marcellus shale better than Langmuir isotherm based on different samples within the formation. ${ }^{11}$ However, this may not necessarily be the case for other shales.
\end{abstract}

The choice of adsorption model to use when accounting for gas adsorption in shale gas reservoirs is critical especially for Gas in Place (OGIP) calculations since inaccurate predictions can affect reporting of overall gas reserves. To that end, different adsorption models would have to be compared and evaluated in order to select the model that fits experimental data accurately. In examining the effect of using different error criteria for determining parameters for shale gas adsorption models, a statistically robust error analysis has been performed based on the sum of normalised error (SNE). Most shale gas adsorption modelling are conducted without finding out the most appropriate error function to use which introduces adsorption prediction errors in calculations. Five different error analysis were used including Sum of squared error (SSE), average relative error (ARE), the sum of absolute error (SAE), Marquardt's Percent standard Deviation (MPSD), and Hybrid fractional error (HYBRID). To account for the influence of temperature in adsorption capacities, the study also compares the use of temperature dependent models, such as Exponential and Bi-Langmuir models for gas adsorption. These models can be conducted at multiple temperatures and ensure adsorption data can be obtained at any temperature beyond laboratory conditions. This is particularly useful when conducting thermal stimulation as an enhanced gas recovery

Gas adsorption modelling involves applying a set of different adsorption models to acquired experimental shale gas adsorption data. These models can be grouped under single component systems or multi-component systems. Under the single component system, a single gas such as methane is used as the adsorbed gas on shale. The advantage of using single component models is that they are very simple and easy to be used in the calculation of adsorbed gas amount. This is especially useful when conducting numerical simulations involving the calculation of adsorption in shale gas reservoirs. For this reason, single component models can be found in a variety of reservoir simulations of shale gas systems. However, this assumption is not valid because in most cases, the formation gas is a mixture containing more than one component. ${ }^{10}$ In shale gas systems, methane, carbon dioxide $(\mathrm{CO} 2)$ and other gases can be found, therefore, modelling the gas adsorption in such systems would require adsorption models capable of addressing the multi-component gas mixture present.

There are lots of factors that can account for the adsorption capacity of methane on shale. These factors include, but not limited to, the total organic content (TOC), the level of thermal maturity of the shale, Kerogen content, Pressure and Temperature. Experimental studies suggested that adsorbed gas quantity versus TOC shows proportional relation to maturity/kerogen type with high TOC of shale leading to high adsorption capacity. ${ }^{12-16}$ Low reservoir pressure will correspond to a much lower adsorbed quantity due to the fact that higher binding energy is required for gas adsorption. ${ }^{17,18}$

Gas adsorption in shale gas reservoir is considered to be an exothermic reaction due to heat loss as a result of the force of attraction between the adsorbate and adsorbent. Therefore, temperature plays an important role in determining the adsorption capacity of shale reservoirs. Higher reservoir temperature will correspond to a lower adsorption capacity of the shale and vice versa. Temperature dependence of adsorption capacity is greatly influenced by the isosteric heat which also depends on the surface coverage. ${ }^{19}$ To be able to account for the adsorption capacity, adsorption models should be expressed not only as a 
function of pressure, but also of temperature. Section 2 of this study is, therefore, focused on describing the various single component systems, multi-component systems and finally temperature-dependent models used in the modelling of shale gas adsorption.

Several works have been conducted on adsorption modelling without taking into consideration the choice of error function used in optimising the adsorption model. , $9,20-22$ This often results in only one set of adsorption constants for the adsorption models being used without any serious interrogation to how accurately it fits the adsorption model to experimental data. According to Sreńscek-Nazzal et al., ${ }^{23}$ very few detailed studies have been conducted on comparing the accuracy of the error functions used in modelling gas adsorption and also the accuracy of the predicted isotherm parameters. No study has however looked at comparing different error functions on modelling gas adsorption in shale gas reservoirs. In minimising the difference between the experimental data and the predicted results from the adsorption models, several error functions have been proposed and applied to predict optimal isotherms including sum of square error (SSE), average relative error (ARE), sum of absolute error (SAE), Marquardt's percent standard deviation (MPSD) and Hybrid fractional error (HYBRID). ${ }^{23-26}$

\section{Shale gas adsorption models}

\section{Single Component Models}

\section{Langmuir Isotherm}

One of the most widely used adsorption isotherms is Langmuir isotherm. ${ }^{6} \mathrm{~A}$ key assumption of Langmuir isotherm is that there must be a homogeneous surface and no interaction between the adjacent molecules. This is, however, a difficult concept to apply even in coal or shale systems, because their internal organic matter is chemically heterogeneous. ${ }^{6}$

Langmuir isotherm is given by the formulae below

$$
V=\frac{V_{L} b p}{1+b p}, \quad \text { Equation } 1
$$

Where $V$ is the volume of adsorbed gas at pressure $P, V_{L}$ is the Langmuir volume or maximum gas adsorption at infinite pressure and $b$ is the Langmuir constant.

\section{BET Model}

BET isotherm was developed in 1938 by Stephen Brunauer, P.H. Emmet and Edward Teller. ${ }^{27} \mathrm{~A}$ key assumption that was used in the derivation of this isotherm is the fact that the adsorption layers on the surface of the organic carbon were infinite. For relatively flat and non-porous surfaces, the use of Langmuir isotherm is often not valid. The BET isotherm is normally considered a better fit in describing the adsorption processes in certain shale gas reservoirs. ${ }^{11}$ The BET

$$
V(P)=\frac{V_{m} C \frac{P}{P_{O}}}{1-\frac{P}{P_{O}}}\left[\frac{1-(n+1)\left(\frac{P}{P_{O}}\right)^{n}+n\left(\frac{P}{P_{O}}\right)^{n+1}}{1+(C-1) \frac{P}{P_{O}}-C\left(\frac{P}{P_{O}}\right)^{n+1}}\right]
$$

Equation 2
$V_{m}$ is the maximum adsorption gas volume when the entire absorbent surface is being covered with a complete monolayer, $C$ is a constant related to the net heat of adsorption, $P_{o}$ the saturation pressure of the gas, which can be calculated from the reduced Kirchoff equation (See supplemenatry sheet ) and $n$ is the maximum number of adsorption layers. When $n=1$, the equation will be reduced to the Langmuir isotherm and when $n=\infty$, the equation reduces to

$$
V_{L}=\frac{V_{m} C P}{\left(P_{o}-P\right)\left[1+\frac{(C-1) P}{P_{o}}\right]_{\text {Equation 3 }}}
$$

\section{Dubinin-Astakhov}

One of the widely used equations for describing experimental data of the adsorption of gases on microporous solids is the Dubinin equations. This equation was proposed by Dubinin and Radushkevich for solids with homogeneous structure of micropores with later extensions of non-homogeneous microporous structures by Dubinin -Astakhov (DA) equations. ${ }^{28}$

A more general form of the D-A equation is:

$$
\begin{aligned}
& W=W_{o} \exp \left[-\left(\frac{R T}{\beta E} \ln \frac{P_{s}}{P}\right)^{m}\right]_{\text {Equation } 4} \\
& D=\frac{R T}{\beta E}
\end{aligned}
$$

When $m$ is equal to 2 , the D-A equation reduces to the D-R equation. The additional parameter $m$ allows for some flexibility of modelling ${ }^{6,29}$ compared with the two-parameter equation of D-R.

\section{Vacancy Solution Model (VSM)}

The vacancy solution model by Suwanayuen and Danner ${ }^{30}$ treats the adsorbed phase as a mixture of adsorbed species and their vacancies. ${ }^{31}$ That is, it assumes two solutions in the system made up of the gas phase and the adsorbed phase. The surface is considered to be made up of a vacancy (species $v$ ) and adsorbed species (species 1). ${ }^{32}$ The VSM has been found to be applicable to all gas adsorption systems. ${ }^{30}$ The vacancy is defined as "vacuum entity occupying a space that can be filled by an adsorbate molecule." The vacancies are imaginary entity with the same size as the adsorbate. In order to account for the non-ideality of the system, activity coefficient obtained from pure component data are used. The VSM has been found to be applicable to all gas adsorption systems. ${ }^{30}$ In view of this, its application could be said to be suitable for shale and coal bed methane systems. There are, however, limited applications of this model in shale gas system. Using the Wilson equation to define the activity coefficient, the Wilson VSM isotherm equation can be obtained for a single component as

$P=\left[\frac{n_{1}^{\infty}}{b_{1}} \frac{\theta}{1-\theta}\right]\left[\Lambda_{1 v} \frac{1-\left(1-\Lambda_{v 1}\right) \theta}{\Lambda_{1 v}+\left(1-\Lambda_{v 1}\right) \theta}\right]$
$\exp \left[-\frac{\Lambda_{v 1}\left(1-\Lambda_{v 1)} \theta\right.}{1-\left(1-\Lambda_{v 1}\right) \theta}-\frac{\left(1-\Lambda_{1 v}\right) \theta}{\Lambda_{1 v}+\left(1-\Lambda_{1 v}\right) \theta}\right]$

Equation 5

For multi-component adsorption calculations, the general form of the 
VSM is given as

$\phi_{i} y_{i} P=\gamma_{i}^{s} x_{i} n_{m}^{s} \frac{n_{i}^{s, \infty} \Lambda_{i 3}}{n_{m}^{s, \infty} b_{i}} \exp \left(\Lambda_{3 i}-1\right) \exp \left(\frac{\pi a_{i}}{R T}\right)$

Equation 6

The fugacity coefficient is set to unity for gas adsorption at moderate pressures. Equation 6 is normally solved by trial and error to obtain $y_{i}$ and $n_{m}^{s}$.

\section{Binary Component Models}

\section{Extended Langmuir Model (EL)}

An extension to the Langmuir isotherm was developed by Markham and Benton ${ }^{33}$ called the extended Langmuir model. This model extends the Langmuir model to include a multi-component system by taking into consideration the partial pressures and molar composition. This model has been used widely in the prediction of multi-component adsorption. One of the main critiques of this model is the issue of thermodynamic inconsistency. For a thermodynamic consistent model, this means the sorption limit must be equal for all the components. ${ }^{6}$ Equation 7 is used to represent the EL model for multi-component systems. ${ }^{34}$

$$
V_{a}=\sum_{i=1}^{n} \frac{V_{L i}\left(P_{g} y_{i}\right)}{P_{L i}+\sum_{j=1}^{n} \frac{1}{P_{L j}}\left(y_{j} P_{g}\right)} \quad \text { Equation 7 }
$$

Where $V_{L i}=$ Langmuir volume constant for pure component I, (SCF/Ton), $P_{L i}=$ Langmuir pressure constant for pure component i, (psia), $y_{i}=$ Gas phase composition of component I, (fraction), $P_{g}$ $=$ Gas phase pressure, (psia), $V_{a}=$ Adsorbed volume of component, (SCF/Ton)

\section{Ideal Adsorbed Solution}

Ideal adsorbed solution theory can be used to predict binary adsorption equilibrium for various mixtures from pure component adsorption data. This theory was first proposed by Meyers and Prausnitz. ${ }^{35}$ For multi-component adsorption prediction, it has quickly established itself as one of the favoured methods. The key assumption under which the IAST was derived was based on the fact that the adsorbed mixture behaves like an ideal adsorbed solution. This is similar to Raoult's law for a bulk solution.

$p y_{i}=p_{i}^{o}(\pi) x_{i}$ Equation 8

$p^{o}{ }_{i}$ is the vapour pressure of the pure component I, at the same spreading pressure and same temperature $\mathrm{T}$, as the adsorbed mixture. $x_{i}$ is the sorbed phase gas mole fraction, $\pi$ is the spreading pressure, where the spreading pressure is defined as the reduction in the surface tension of the surface as the adsorbate spreads over the surface ${ }^{36}$ The relationship between $p_{i}^{o}$ and $\pi_{i}$ is expressed as

$$
\pi_{i}^{*}=\frac{\pi_{i} A^{\prime}}{R T}=\int_{0}^{p_{i}^{o}} \frac{n_{a}(p)}{p} d p \quad \text { Equation } 9
$$

The condition below needs to be satisfied for both adsorbed mole fractions and mole fractions of the free gas.

$$
\begin{aligned}
& \sum_{j=1}^{N} y_{i}=1 \\
& \sum_{j=1}^{N} x_{i}=1,
\end{aligned}
$$

Total adsorbed gas in the mixture is given as

$$
\frac{1}{n_{t}}=\sum_{i=1}^{n_{c}} \frac{x_{i}}{n_{i}^{o}} \quad \text { Equation } 10
$$

The amount of each component adsorbed in the mixture is given as $n_{i}=n_{t} x_{i}$

Any pure component adsorption isotherm could be used in the above equation to evaluate the spreading pressure.

\section{Temperature Dependent Models}

Adsorption in shale gas reservoirs is not only a function of pressure but also temperature. Hence, adsorption models should be able to predict the adsorption capacities at several temperatures. The existence of a geothermal gradient in most reservoirs implies, temperature differential at different depths in the reservoir and due to the effect of temperature on gas adsorption, the original gas in place will differ at different depths. ${ }^{21}$ Two of the most widely used temperature-dependent adsorption models are the Bi-Langmuir model and the Exponential model.

\section{Bi-Langmuir Model}

Lu et al., ${ }^{13}$ conducted studies on Devonian shales and observed that the adsorption capacity of Devonian shales decreased at increasing temperature. They proposed the use of Bi-Langmuir model to describe the gas adsorption at several temperatures. The model describes gas adsorption on an adsorbent based on having two discrete sharp peaks of energy distribution. They noted that clay and kerogen mineral components are two main factors responsible for gas storage in Devonian shales. Thus, one term of the equation describes the gas adsorption on clay minerals and the other describing gas adsorption on kerogen.

$$
\begin{aligned}
& \frac{N_{a d s}}{N_{m}}=f_{1} \frac{k_{1}(T) p}{1+k_{1}(T) p}+\left(1-f_{1}\right) \frac{k_{2}(T) p}{1+k_{2}(T) p} \\
& k(T)=k_{0} T^{-1 / 2} \exp (-E / R T)
\end{aligned}
$$
Equation 11

$f=$ fraction of adsorption site, $k=$ adsorption equilibrium constant, $N_{m}$ =amount of adsorbed gas per unit volume adsorbent, scf/ft3, $E=$ Adsorption energy

\section{Exponential Model}

The assumption of constant Langmuir volume is not always true and this has been argued by various researchers by conducting experiments to show the dependency of Langmuir volume on temperature. Thus, 
the Langmuir volume decreases with increasing temperature. ${ }^{13,16,37}$ Ye et al., ${ }^{37}$ defined a new improved Langmuir model that took into account the temperature dependency of the Langmuir volume. By modifying the Langmuir constant to be a function of temperature, a new exponential relation was defined between Langmuir constant and temperature as

$V_{L}=V_{s} \exp \left(-D_{T} T\right) \quad$ Equation 12

The final modified model referred to as the Exponential model is written below

$$
V=\frac{V_{s} \exp \left(-D_{T} T\right) p}{p+\sqrt{T} /[A \exp (B / T)]} \text { Equation } 13
$$

The coefficients $V_{s}, D_{T}, A, B$ in Equation 11 can be determined by fitting the experimental adsorption data.

\section{Adsorption model parameter determination using Non-Linear Regression}

\section{Sum of Squared Error Function (SSE)}

This is probably the most common of all the error functions. It is given as

$$
S S E=\sqrt{\left(\sum_{i=1}^{N} X_{i c a l}-X_{i \exp }\right)^{2}} \quad \text { Equation } 14
$$

\section{Average Relative Error Function (ARE)}

This has been used by many researchers to find optimal adsorption model in shale/coal gas reservoirs. ${ }^{6,21,38}$ It involves minimising the fractional error distribution across the whole range of independent variables. $^{23,24}$ This is defined as

$$
A R E=100 * A B S\left\{\frac{\sum_{i=1}^{N}\left[\left(\left(X_{i c a l}-X_{i \exp }\right) / X_{i \exp }\right)\right]}{N}\right\}
$$

Equation 15

\section{Sum of Absolute Error Function (SAE)}

This is seen as very similar to Sum of Squared Error and is given as $S A E=\sum_{i=1}^{N}\left|X_{i c a l}-X_{i \exp }\right| \quad$ Equation 16

\section{Marquardt's Percent Standard Deviation (MPSD)}

This is often seen as an ideal error function in most adsorption studies. ${ }^{23,39}$ It can be expressed as

$$
M P S D=100 \sqrt{\frac{1}{N-p}} \sum_{i=1}^{N}\left(\frac{X_{i c a l}-X_{i \exp }}{X_{i \exp }}\right)^{2} \text { Equation } 17
$$

\section{HYBRID Fractional Error Function (HYBRID)}

At low-pressure values, the HYBRID function improves the overall fitting of the model to the experimental data compared to some of the other error functions such as SSE.

$$
H Y B R I D=\frac{100}{N-p} \sum_{i=1}^{N}\left(\frac{\left(X_{i c a l}-X_{i \exp }\right)^{2}}{X_{i \exp }}\right)
$$

Equation 18

\section{Sum of Normalised Error (SNE)}

Non-linear regression is mostly preferred to linear regression due to inherent bias resulting from linearization. ${ }^{24,40}$ According to Porter et al. ${ }^{40}$ due to the different set of isotherm parameters produced by the different error criteria, results were obtained by finding normalised results for each parameter set for each isotherm model and combining them. The procedure involved obtaining the value of errors for each error function for each set of isotherm constants and dividing by the maximum errors for that error function. ${ }^{23}$ Each parameter has been obtained by minimising the error functions across the gas pressures by using Microsoft Excel Solver add-in.

To conduct the modelling for this studies, three cases have been studied. The first case study uses data from Chareonsuppanimit et al., ${ }^{20}$ of gas adsorption of methane, $\mathrm{CO} 2$ and Nitrogen on Albany shale. The second case study uses data obtained from Valenzuela and Myers ${ }^{41}$ referencing adsorption data on activated carbon by Szepesy and Illés. ${ }^{42}$ This data have been used primarily to evaluate single and multi-component component adsorption system. The final case study uses data from Zhang et al. ${ }^{16}$ to evaluate temperature-dependent models.

\section{Experimental Data}

Obtaining experimental data for shale gas modelling is a challenging task due to the low adsorption capacities and the range of pressure and temperature under which experiments are conducted. ${ }^{8}$ Reports of inconsistent results from measurements observed at higher pressures and the lack of available quality database have also contributed to challenges in this area. In particular, very limited experimental binary gas adsorption data on shale are available. Due to this scarcity of available data, adsorption capacity on activated carbon is mostly used by many researchers to model the performance of adsorption model in predicting binary mixtures of gas adsorption capacities on shale. Fitzgerald et al., ${ }^{43}$ argued that experimental uncertainty in the use of activated carbon is lower compared to coal which has a similar structure to shale. Also, because coal/ shale has a more complex structure pore to activated carbon, the adsorption on activated carbon can serve as a reference for more complicated adsorption/desorption on coal $/$ shale. ${ }^{44}$

Model comparison is essential in the study of their capabilities and limitations when fitting pure component isotherms as well as for predicting multi-component systems. Adsorption data of Methane, Carbon dioxide and Nitrogen on New Albany shale have been 
obtained from the literature Chareonsuppanimit et al., ${ }^{20}$ to model single component gas adsorption. For the purpose of showing the performance of the different binary adsorption models, data of Activated carbon from Szepesy and Illés, ${ }^{42}$ have been used. For temperature dependent models, pure component data of shale obtained at several temperatures in Green River shale ${ }^{16}$ have been used to evaluate their performance. All adsorption data obtained from literature and used in this article have been provided in supplementary sheets Table S1-S4.

\section{Results and Discussion}

\section{Single Component Analysis}

Tables 1-4 present a set of adsorption isotherm parameters for different adsorption models and the error analysis involving the use of SNE. The values obtained by the use of SNE have been compared to identify parameters of the isotherms that can provide the most accurate match to the measured data on New Albany shale. The bold numbers represent the minimum SNE for each of the isotherm and their associated optimum parameter set for different gas adsorption.

From Table 1 and Table S6, we can observe the Langmuir isotherm parameters and SNE values for New Albany shale for Methane, Carbon dioxide and Nitrogen. Similar values can be easily observed for the different error functions used in that analysis. The SNE values are very similar for the different gas adsorption with the exception of methane, which showed a much higher SNE for SAE compared with the other error functions. Also, the Langmuir parameter constants $V_{L}$ and $b$ are quite similar in magnitude. Overall, we can see that the Langmuir isotherm provided a good fit to the New Albany datasets. ARE provided the best match parameters for Langmuir isotherm of methane and $\mathrm{CO} 2$ gas whilst SSE gave the best match for the case of nitrogen adsorption using Langmuir isotherm. Overall the Langmuir isotherm is recommended for modelling the experimental data for New Albany shale for Methane and CO2. As can be observed in Figure 1, the Langmuir isotherm fits very well with the experimental data regardless of which error function is chosen.

Table I SNE for Non-linear Langmuir isotherm

\begin{tabular}{llllll}
\hline & SSE & ARE & SAE & MPSD & HYBRID \\
\hline $\begin{array}{l}\text { Methane } \\
\text { SNE }\end{array}$ & 2.0456 & 2.0083 & 5 & 2.1427 & $2.24 I 1$ \\
$\begin{array}{l}\text { Carbon Dioxide } \\
\text { SNE }\end{array}$ & 4.2552 & 3.6307 & 4.0848 & 4.2752 & 4.2320 \\
$\begin{array}{l}\text { Nitrogen } \\
\text { SNE }\end{array}$ & 3.9504 & 4.0152 & 4.1666 & 4.0152 & 4.2265 \\
\hline
\end{tabular}

Table 2 SNE for Non-Linear BET model using Equation 3

\begin{tabular}{|c|c|c|c|c|c|}
\hline & SSE & ARE & SAE & MPSD & HYBRID \\
\hline \multicolumn{6}{|c|}{ Methane } \\
\hline SNE & 4.668 & 4.7349 & 4.7410 & 4.8365 & 4.7780 \\
\hline \multicolumn{6}{|c|}{$\mathrm{CO}_{2}$} \\
\hline SNE & $4.948 I$ & 3.9526 & 4.8955 & 4.9129 & 4.9076 \\
\hline \multicolumn{6}{|c|}{ Nitrogen } \\
\hline SNE & 4.0081 & 3.9433 & 4.2248 & 3.9650 & 4.1983 \\
\hline
\end{tabular}

Table 3 SNE for Non-linear Dubinin -Astakhov isotherm

\begin{tabular}{|c|c|c|c|c|c|}
\hline & SSE & ARE & SAE & MPSD & HYBRID \\
\hline \multicolumn{6}{|c|}{ Methane } \\
\hline SNE & 3.5769 & 3.5619 & 4.7807 & 3.5619 & 3.8472 \\
\hline \multicolumn{6}{|c|}{$\mathrm{CO}_{2}$} \\
\hline SNE & 4.3903 & 4.5538 & 4.7416 & 4.5539 & 4.3059 \\
\hline \multicolumn{6}{|c|}{ Nitrogen } \\
\hline SNE & 3.4763 & 3.9055 & 3.8840 & 3.9055 & $3 .|448|$ \\
\hline
\end{tabular}

Table 4 SNE for Non-linear Vacancy solution model

\begin{tabular}{|c|c|c|c|c|c|}
\hline & SSE & ARE & SAE & MPSD & HYBRID \\
\hline \multicolumn{6}{|c|}{ Methane } \\
\hline SNE & 4.6122 & 4.1126 & 4.4328 & 4.1071 & 4.1482 \\
\hline \multicolumn{6}{|c|}{$\mathrm{CO}_{2}$} \\
\hline SNE & $4.6 \mid 45$ & 3.9830 & 3.6623 & 3.9830 & 3.7010 \\
\hline \multicolumn{6}{|c|}{ Nitrogen } \\
\hline SNE & 4.9796 & 3.98022 & 3.9921 & 3.9884 & 4.0611 \\
\hline
\end{tabular}




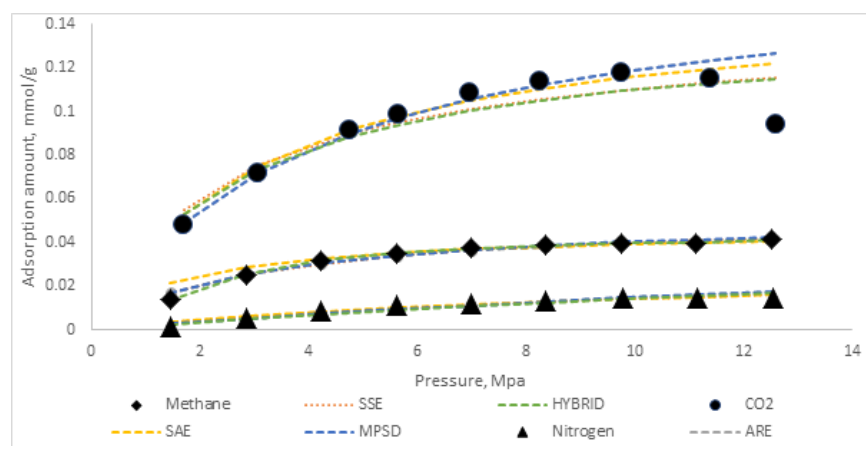

Figure I Experimental data for Methane, $\mathrm{CO}_{2}$ and Nitrogen and Langmuir isotherm obtained by SSE, ARE, SAE, MPSD and HYBRID

The BET isotherm constants and error analysis using the different error functions are shown in Table 2 and Table S7 for methane, $\mathrm{CO} 2$ and nitrogen adsorption. It can also be observed that the parameters for BET for all the error functions are very similar with slight variations. Similarly, the SNE values are very much similar. Comparing the SNE values, it can be concluded that SSE for methane, ARE for $\mathrm{CO} 2$ and nitrogen provided the best BET fit for the experimental data for New Albany shale. However, Figure S3 confirms that BET isotherm cannot be used for modelling $\mathrm{CO} 2$ adsorption on New Albany shale data even though, there was a better match for Methane and Nitrogen adsorption using BET.

Non - linear modelling of D-A equation with different error functions also showed similar values for the D-A constants (see Table 3 and Table S8). However, for nitrogen adsorption, MPSD showed a much higher value for $V_{L}$ compared with the rest of the error functions. Comparing the SNE also shows that, ARE is a much better fit for methane gas adsorption using D-A, whereas HYBRID error function showed the closest fit for $\mathrm{CO} 2$ adsorption and Nitrogen adsorption. Observing Figures S1-S3 shows that D-A model was however not the best model to use for modelling methane, $\mathrm{CO} 2$ and Nitrogen adsorption on New Albany shale.

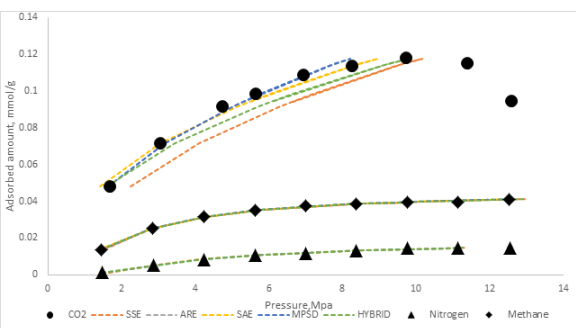

Figure SI Experimental data for Methane, $\mathrm{CO}_{2}$ and Nitrogen and VSM obtained by SSE, ARE, SAE, MPSD and HYBRID

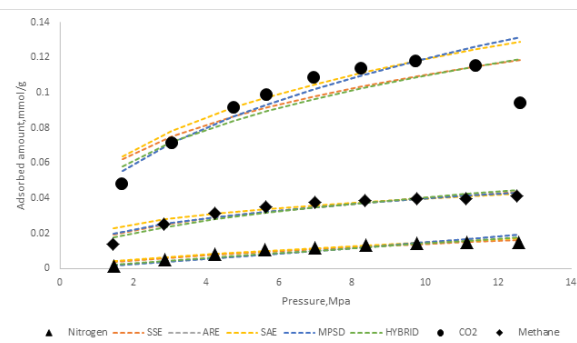

Figure S2 Experimental data for Methane, $\mathrm{CO}_{2}$ and Nitrogen and D-A obtained by SSE, ARE, SAE, MPSD and HYBRID

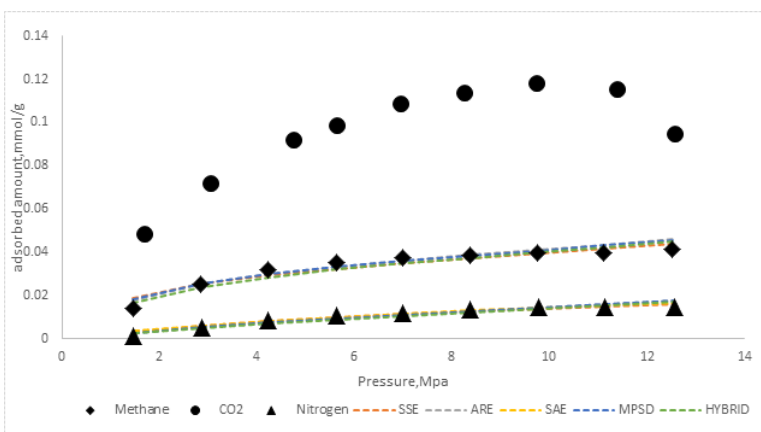

Figure S3 Experimental data for Methane, $\mathrm{CO}_{2}$ and Nitrogen and $\mathrm{BET}$ isotherm obtained by SSE, ARE, SAE, MPSD and HYBRID

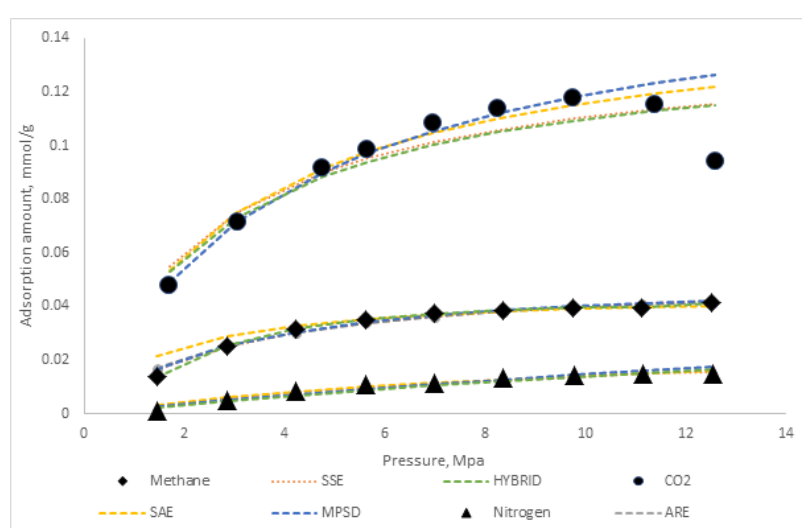

Figure S4 Experimental data for Methane, CO2 and Nitrogen and Langmuir isotherm obtained by SSE, ARE, SAE, MPSD and HYBRID

Table 4 and Table S9 presents the VSM parameters and the error analysis using different error functions. Overall, just like previous adsorption models, the model parameters for VSM were very similar to all the error functions used. In terms of the SNE comparison, it can be noticed that SSE showed consistently higher values for methane, $\mathrm{CO} 2$ and Nitrogen adsorption on shale whereas the remaining SNE for the other error functions were generally quite similar. MPSD was the best error function to be used for methane adsorption whilst SAE was found to be best for $\mathrm{CO} 2$ adsorption. ARE was also found to be most suited for modelling nitrogen adsorption using VSM on New Albany shale.

Out of the overall 12 different results for SNE calculations, SSE and HYBRID produced parameter sets showing the minimum sum of normalised error in only 2 of the results. ARE provided 6 minimum SNE out of the total 12, proving to be the most consistent error function to be used in shale gas adsorption modelling. Finally, SAE and MPDS provided only a single result showing minimum SNE for all the results generated. From observation of Tables 1- 4 and Figures S1-S4, it can also be deduced that Langmuir isotherm provides the best overall fit for the data on all of the gas adsorption involving methane and $\mathrm{CO} 2$ with the exception of nitrogen adsorption where D-A proved to be the best fit for the experimental data.

\section{Binary gas Analysis}

Adsorption data for methane and ethane on activated carbon at a temperature of $293.15 \mathrm{k}$ have been reported by Szepesy and Illés. ${ }^{42}$ Pressures for pure component adsorption data were extended up to $124 \mathrm{KPa}$. The use of pure adsorption models to represent adsorption 
data is significant when modelling shale gas reservoir simulation. Very often, Langmuir equation has been used to represent pure adsorption data due to the ease with which it can represent the data and also its use in numerical reservoir simulators. In order to conduct binary gas adsorption modelling, results from pure components are used to obtain adsorption prediction. For this study, VSM and Langmuir's isotherm has been used to conduct the pure component adsorption modelling and later used in carrying out the binary adsorption prediction. The results from single component modelling using Langmuir and VSM are shown in Tables 5-6.

Table 5 SNE for binary mixture of methane and ethane (Langmuir isotherm)

\begin{tabular}{lllcll}
\hline & SSE & ARE & SAE & MPSD & HYBRID \\
\hline \multirow{2}{*}{ SNE } & & \multicolumn{4}{c}{ Methane } \\
& 4.9668 & $\mathbf{4 . 9 1 6 9}$ & 4.9358 & 4.9358 & 4.9235 \\
& SSE & ARE & Ethane & MPSD & HYBRID \\
SNE & 4.2434 & 4.5727 & 4.3382 & 4.5728 & $\mathbf{4 . 2 0 2 4}$ \\
\hline
\end{tabular}

Table 6 SNE for binary mixture of methane and ethane (Vacancy solution model)

\begin{tabular}{|c|c|c|c|c|c|}
\hline & SSE & ARE & SAE & MPSD & HYBRID \\
\hline \multicolumn{6}{|c|}{ Methane } \\
\hline SNE & 1.7534 & 1.6184 & 1.6436 & 1.6092 & 5 \\
\hline \multicolumn{6}{|c|}{ Ethane } \\
\hline & SSE & ARE & SAE & MPSD & HYBRID \\
\hline SNE & 4.0883 & 3.4805 & 3.5592 & 3.6697 & 3.6697 \\
\hline
\end{tabular}

Table SI Excess adsorption data of Methane and Nitrogen in Albany Shale. ${ }^{20}$

\begin{tabular}{|c|c|c|c|c|c|}
\hline \multirow{2}{*}{$\begin{array}{l}\text { Methane } \\
\text { Pressure (MPa) }\end{array}$} & \multirow[b]{2}{*}{$\begin{array}{l}\text { Excess adsorption } \\
(\mathrm{mmol} / \mathrm{g})\end{array}$} & \multirow{2}{*}{$\begin{array}{l}\text { Nitrogen } \\
\text { Pressure } \\
\text { (MPa) }\end{array}$} & \multirow[b]{2}{*}{$\begin{array}{l}\text { Excess adsorption } \\
(\mathrm{mmol} / \mathrm{g})\end{array}$} & \multicolumn{2}{|c|}{ Carbon dioxide } \\
\hline & & & & $\begin{array}{l}\text { Pressure } \\
(\mathrm{MPa})\end{array}$ & $\begin{array}{l}\text { Excess adsorption } \\
(\mathrm{mmol} / \mathrm{g})\end{array}$ \\
\hline 1.45 & 0.0138 & 1.47 & 0.0012 & 1.7 & 0.0479 \\
\hline 2.85 & 0.0253 & 2.86 & 0.0052 & 3.06 & 0.0715 \\
\hline 4.23 & 0.0316 & 4.23 & 0.0083 & 4.76 & 0.0916 \\
\hline 5.63 & 0.0352 & 5.62 & 0.0109 & 5.66 & 0.0985 \\
\hline 6.99 & 0.0374 & 6.99 & 0.0116 & 6.96 & 0.1085 \\
\hline 8.36 & 0.0386 & 8.37 & 0.0133 & 8.26 & 0.1136 \\
\hline 9.76 & 0.0395 & 9.77 & 0.0145 & 9.75 & 0.1179 \\
\hline 11.12 & 0.0397 & 11.14 & 0.0147 & 11.4 & 0.115 \\
\hline 12.52 & 0.0412 & 12.56 & 0.0147 & 12.6 & 0.0942 \\
\hline
\end{tabular}

Table S2 Single component Adsorption data for Methane and Ethane on Activated Carbon. ${ }^{41}$

\begin{tabular}{llll}
\hline & \multicolumn{1}{c}{ Ethane } & \multicolumn{1}{c}{$\begin{array}{l}\text { Methane } \\
\mathrm{P}(\mathrm{mmol} / \mathrm{g})\end{array}$} \\
\hline 0.56 & $\mathrm{n}(\mathrm{mmol} / \mathrm{g})$ & $\mathrm{P}(\mathrm{Kpa})$ & 0.1919 \\
2.3465 & 0.2432 & 16.0253 & 0.2972 \\
2.5331 & 0.547 & 27.3577 & 0.3061 \\
4.5729 & 0.485 & 31.464 & 0.3654 \\
4.7329 & 0.8049 & 34.6371 & 0.4556 \\
7.706 & 0.8018 & 46.5294 & 0.464 \\
9.5325 & 1.0642 & 48.0626 & 0.5216 \\
11.7723 & 1.169 & 54.5687 & 0.5725 \\
15.1987 & 1.3238 & 62.608 & 0.6662
\end{tabular}




\begin{tabular}{llll}
17.2385 & 1.6063 & 83.4462 & 0.7103 \\
24.3446 & 1.8785 & 83.6329 & 0.6876 \\
28.4642 & 1.9802 & 94.0587 & 0.8089 \\
32.0373 & 2.1167 & 99.8715 & 0.8143 \\
37.0635 & 2.2399 & 112.8304 & 0.8785 \\
43.9563 & 2.4108 & 124.8694 & 0.9424 \\
50.0624 & 2.5402 & & \\
54.2621 & 2.6169 & & \\
60.4615 & 2.72 & & \\
68.3275 & 2.8458 & & \\
72.5938 & 2.8967 & & \\
85.0728 & 3.0658 & & \\
85.2327 & 3.0497 & & \\
101.9913 & 3.2393 & & \\
113.257 & 3.3576 & & \\
\hline
\end{tabular}

Table S3 Binary gas Mixture of Ethane and Methane on activated carbon at temperature of 293.15K.41

\begin{tabular}{llll}
\hline $\mathrm{P}(\mathrm{Kpa})$ & $\mathrm{yl}($ Ethane $)$ & $\mathrm{xl}($ Ethane $)$ & $\mathrm{n}(\mathrm{mmol} / \mathrm{g})$ \\
\hline 101.191 & 0.066 & 0.605 & 1.3456 \\
99.7249 & 0.083 & 0.658 & 1.4116 \\
102.485 & 0.245 & 0.852 & 2.0652 \\
99.7249 & 0.251 & 0.859 & 2.054 \\
99.7249 & 0.489 & 0.941 & 2.6255 \\
102.538 & 0.519 & 0.953 & 2.7692 \\
99.7515 & 0.731 & 0.975 & 2.9887 \\
\hline
\end{tabular}

Table S4 Adsorption capacities of Green River Shale formation at several temperatures. ${ }^{16}$

\begin{tabular}{|c|c|c|c|c|c|}
\hline \multicolumn{2}{|c|}{$\begin{array}{c}\text { Temp } \\
35.4 \mathrm{C}\end{array}$} & \multicolumn{2}{|c|}{$\begin{array}{c}\text { Temp } \\
50.4 \mathrm{C}\end{array}$} & \multicolumn{2}{|c|}{$\begin{array}{c}\text { Temp } \\
65.4 \mathrm{C}\end{array}$} \\
\hline Pressure & Adsorbed quantities & Pressure & Adsorbed quantities & Pressure & Adsorbed quantities \\
\hline P(Мрa) & $\mathrm{m} 3 / \mathrm{kg}$ & $\mathrm{P}($ Mpa $)$ & $\mathrm{m} 3 / \mathrm{kg}$ & $\mathrm{P}($ Mpa $)$ & $\mathrm{m} 3 / \mathrm{kg}$ \\
\hline 0.871842 & 0.003752 & $0.69650 \mathrm{I}$ & 0.00177 & 0 & 0 \\
\hline 2.153814 & 0.006729 & 1.724883 & 0.003702 & 0.822757 & 0.00161 \\
\hline 3.862286 & 0.009654 & 3.053614 & 0.005876 & 2.009244 & 0.003703 \\
\hline 5.412166 & 0.011802 & 4.555932 & 0.007809 & 3.369508 & 0.005797 \\
\hline 7.040655 & 0.013469 & 6.31131 & 0.010119 & 5.014048 & 0.007785 \\
\hline $8.60557 \mid$ & 0.014653 & 8.176682 & 0.011679 & 8.239239 & 0.010876 \\
\hline 10.05973 & 0.015623 & 9.89964 & 0.012945 & 9.993983 & 0.012383 \\
\hline 11.5453 & 0.016352 & II.49609 & 0.014049 & || $.5745 \mid$ & 0.013326 \\
\hline 12.76197 & 0.016651 & 12.96573 & 0.014617 & $|2.7440|$ & 0.01392 \\
\hline 13.56795 & 0.017029 & 13.7876 & 0.015102 & 13.5184 & 0.014298 \\
\hline 14.07355 & 0.0171111 & 14.38809 & 0.015319 & 13.97675 & 0.014568 \\
\hline
\end{tabular}


Table S5 Best fitted parameters for Bi-Langmuir and Exponential model for Green River formation

\section{Bi-Langmuir model}

\begin{tabular}{|c|c|c|c|c|c|c|c|}
\hline Sample & Reference & $N_{m} s t d m^{3} / \mathrm{kg}$ & $k_{1} 1 / M p a$ & $k_{2} 1 / M p a$ & $-E_{1} J /$ mol & $-E_{2} J / m o l$ & $f_{1}$ \\
\hline $\begin{array}{l}\text { Green River } \\
\text { Formation }\end{array}$ & $\begin{array}{l}\text { Zhang et al } \\
2012\end{array}$ & 0.236 & 0.000204 & 0.0124 & 7290.85 & 13703.5 & 0.0053 \\
\hline \multicolumn{8}{|c|}{ Exponential model } \\
\hline Sample & Reference & $V_{s} s t d m^{3} / \mathrm{kg}$ & $D_{t} 1 / K$ & $A K^{1 / 2} / M p a$ & $B K$ & & \\
\hline $\begin{array}{l}\text { Green River } \\
\text { Formation }\end{array}$ & $\begin{array}{l}\text { Zhang et al } \\
2012\end{array}$ & 0.2389 & 0.000398 & 0.573 & $|6.06|$ & & \\
\hline
\end{tabular}

Table S6 Non-linear Langmuir isotherm parameters

\begin{tabular}{llllll}
\hline & SSE & ARE & SAE & MPSD & HYBRID \\
\hline$V_{L}$ & 0.05258 & 0.05158 & 0.04554 & 0.0527 & 0.0545 \\
$b$ & 0.31918 & 0.33769 & 0.61055 & 0.3057 & $0.281 \mathrm{I}$ \\
$V_{L}$ & 0.139438 & 0.167666 & 0.152714 & 0.167668 & 0.14103 \\
$b$ & 0.38098 & 0.24297 & 0.31488 & 0.24297 & 0.35303 \\
$V_{L}$ & 0.03127 & 0.0573 & 0.0295 & & 0.0628 \\
$b$ & 0.0815 & 0.0346 & 0.0924 & 0.0573 & 0.0288
\end{tabular}

Table S7 Non-linear BET isotherm parameters

\begin{tabular}{|c|c|c|c|c|c|}
\hline & SSE & ARE & SAE & MPSD & HYBRID \\
\hline \multicolumn{6}{|c|}{ Methane $\quad P_{o}=46.18 \mathrm{Mpa}$} \\
\hline$V_{m}$ & 0.0351 & 0.0355 & 0.0346 & 0.0362 & 0.0363 \\
\hline$C$ & 30.3761 & 30.447 & 33.0086 & 28.768 & 24.386 \\
\hline \multicolumn{6}{|c|}{$\mathrm{CO}_{2} \quad P_{o}=12.84_{\mathrm{Mpa}}$} \\
\hline$V_{m}$ & 0.002484 & 0.001766 & 0.001763 & 0.001766 & 0.002421 \\
\hline$C$ & 12.220 & 6.6377 & 13.408 & 6.6379 & 341.769 \\
\hline \multicolumn{6}{|c|}{ Nitrogen $\quad P_{o}=104.05 \mathrm{Mpa}$} \\
\hline$V_{m}$ & 0.0223 & 0.0327 & 0.02221 & 0.0327 & 0.03459 \\
\hline$C$ & 12.32225 & 6.4517 & 13.184 & 6.4518 & 5.4748 \\
\hline
\end{tabular}


Table S8 Non-linear Dubinin -Astakhov isotherm parameter

\begin{tabular}{lllcll}
\hline & SSE & ARE & SAE & MPSD & HYBRID \\
\hline$W_{o}$ & & & Methane & \\
$D$ & 0.071649 & 0.069431 & 0.06104 & 0.06943 & 0.0787 \\
$m$ & 2.46547 & 2.517542 & 2.16262 & 2.51754 & 2.4096 \\
$W_{o}$ & 0.935167 & 0.913509 & 0.60568 & 0.91350 & 1.0465 \\
$D$ & & & & 0.1198 \\
$m$ & 0.11932 & 0.13277 & 0.129899 & 0.1327 & 1.96157 \\
$W_{o}$ & 2.16333 & 2.55759 & 2.78645 & 2.5415 & 0.69851 \\
$D$ & 0.694976 & 1.10380 & 0.98100 & 1.09688 & 0.12384 \\
$m$ & & & Nitrogen & & 1.44084 \\
\hline
\end{tabular}

Table S9 Non-linear Vacancy Solution Model isotherm parameters

\begin{tabular}{|c|c|c|c|c|c|}
\hline & SSE & ARE & SAE & MPSD & HYBRID \\
\hline \multicolumn{6}{|c|}{ Methane } \\
\hline$n_{1}^{\infty}$ & 0.04687 & 0.046 & 0.04652 & 0.046469 & 0.04628 \\
\hline$b_{1}$ & 0.0008 & 0.00609 & 0.0066 & 0.003909 & 0.0039 \\
\hline$\Lambda_{1 v}$ & 0.0428 & 0.3676 & 0.3468 & 0.0901 & 0.08905 \\
\hline$\Lambda_{v 1}$ & I.359807 & 0.9440 & 1.0706 & 1.6863 & 1.7015 \\
\hline \multicolumn{6}{|c|}{$\mathrm{CO}_{2}$} \\
\hline$n_{1}^{\infty}$ & 0.59801 & 0.51319 & 0.50157 & 0.51319 & 0.43465 \\
\hline$b_{1}$ & 0.016474 & 0.028472 & $0.03568 \mathrm{I}$ & 0.02847 & 0.0357 \\
\hline$\Lambda_{1 v}$ & 0.03407 & 0.01539 & 0.0086 & 0.01539 & 0.01168 \\
\hline$\Lambda_{v 1}$ & 5.0910 & 5.4004 & 6.2924 & 5.4004 & 5.9118 \\
\hline \multicolumn{6}{|c|}{ Nitrogen } \\
\hline$n_{1}^{\infty}$ & 0.020314 & 0.019184 & 0.019127 & 0.019264 & 0.01926 \\
\hline$b_{1}$ & $0.000 I 57$ & 0.000248 & 0.00025 & 0.000255 & 0.00025 \\
\hline$\Lambda_{1 v}$ & 0.0324 & 0.0225 & 0.0230 & 0.0233 & 0.0233 \\
\hline$\Lambda_{v 1}$ & 1.4750 & 1.7980 & 1.7845 & 1.8005 & 1.810 \\
\hline
\end{tabular}


From both Tables S10-S11, the individual Langmuir and VSM parameters are very similar irrespective of the error function that was used. For methane adsorption, the sum of normalised error was minimum for ARE compared to the rest of the error function when Langmuir isotherm was used as the adsorption model (Table 5). ARE also proved to be the best fit for ethane adsorption when modelling with VSM (Table 6). The HYBRID error function was however found to fit the model better when using Langmuir isotherm whilst it was found to be a worse fit for methane adsorption using VSM. MPSD was the most appropriate error function to be used in methane adsorption when using VSM. The results from Table 5-6 also indicate that VSM would be the preferred adsorption model to be used in modelling single component adsorption for this data set.

Table SIO Langmuir isotherm parameters and for methane and ethane adsorption

\begin{tabular}{|c|c|c|c|c|c|}
\hline & SSE & ARE & SAE & MPSD & HYBRID \\
\hline \multicolumn{6}{|c|}{ Methane } \\
\hline$V_{L}$ & $2.588 \mathrm{I}$ & 2.5544 & 2.4963 & 2.4963 & 2.5215 \\
\hline$b$ & 0.0045 & 0.0046 & 0.0048 & 0.0048 & 0.0047 \\
\hline \multicolumn{6}{|c|}{ Ethane } \\
\hline & SSE & ARE & SAE & MPSD & HYBRID \\
\hline$V_{L}$ & 3.83889 & 3.4501 & 3.8474 & 3.4500 & 3.5981 \\
\hline$b$ & 0.04272 & 0.0578 & 0.0415 & 0.0578 & 0.0525 \\
\hline
\end{tabular}

Table SII Vacancy Solution Model isotherm parameters for methane and ethane adsorption

\begin{tabular}{|c|c|c|c|c|c|}
\hline & SSE & ARE & SAE & MPSD & HYBRID \\
\hline \multicolumn{6}{|c|}{ Methane } \\
\hline$n_{1}^{\infty}$ & 0.046875 & 0.046 & 0.0465 & 0.0464 & 0.0462 \\
\hline$b_{1}$ & 0.000896 & 0.00609 & 0.0066 & 0.0039 & 0.00393 \\
\hline$\Lambda_{1 v}$ & 0.042834 & 0.3676 & 0.3468 & 0.0901 & 0.0890 \\
\hline$\Lambda_{v 1}$ & 1.3598 & 0.9440 & 1.0706 & 1.6863 & 1.7015 \\
\hline \multicolumn{6}{|c|}{ Ethane } \\
\hline & SSE & ARE & SAE & MPSD & HYBRID \\
\hline$n_{1}^{\infty}$ & 5.3946 & 4.6175 & 4.5928 & 4.5721 & 4.5721 \\
\hline$b_{1}$ & 0.1071 & 0.2053 & 0.2171 & 0.2043 & 0.2043 \\
\hline$\Lambda_{1 v}$ & 0.0274 & 0.0122 & 0.0124 & 0.0126 & 0.0126 \\
\hline$\Lambda_{v 1}$ & 4.6475 & 5.325 & 5.3512 & 5.2764 & 5.2764 \\
\hline
\end{tabular}

Table SI 2 Best fitted parameters for validation and extrapolation of temperature to $65^{\circ} \mathrm{C}$

Bi-Langmuir model

\begin{tabular}{llllllll} 
Sample & Reference & $N_{m} s t d m^{3} / \mathrm{kg}$ & $k_{1} 1 / \mathrm{Mpa}$ & $k_{2} 1 / \mathrm{Mpa}$ & $-E_{1} \mathrm{~J} / \mathrm{mol}$ & $-E_{2} J / m o l$ & $f_{1}$ \\
\hline $\begin{array}{l}\text { Green River } \\
\text { Formation }\end{array}$ & $\begin{array}{l}\text { Zhang et al } \\
2012\end{array}$ & 0.22 & 0.000214 & 0.0114 & 7290.85 & 12703.5 & 0.0053
\end{tabular}


Exponential model

\begin{tabular}{|c|c|c|c|c|c|}
\hline Sample & Reference & $V_{s} s t d m^{3} / \mathrm{kg}$ & $D_{t} 1 / K$ & $A K^{1 / 2} / M p a$ & $B K$ \\
\hline $\begin{array}{l}\text { Green River } \\
\text { Formation }\end{array}$ & $\begin{array}{l}\text { Zhang et al } \\
2012\end{array}$ & 0.23 & 0.000378 & 0.573 & 16.261 \\
\hline
\end{tabular}

Binary gas adsorption modelling can now be made once pure component adsorption model fitting has been completed. Throughout this study, EL, IAS and the VSM have been used. The different multicomponent adsorption models have already been discussed in the previous section.

Furthermore, Figures 2-3 show the predictions of the binary gas-phase diagrams for each of the models at a pressure of $101 \mathrm{Kpa}$. The phase diagrams shown in Figures 2-3 show the plots of mole fraction of both Ethane and Methane in the adsorbed phase versus mole fractions in the free gas phase (non-sorbed) while is the plot of mole fraction of methane in sorbed phase versus the total gas adsorption. The predictions show each of the multi-component adsorption models was able to fit closely to the experimental binary adsorption data with different level of accuracy. The Extended Langmuir showed the worst fit compared with both the Ideal adsorbed solution and the Vacancy solution model. The Vacancy solution model was, however, able to fit more accurately for predicted equilibrium compositions in Figures 2-4. EL predicted more ethane in the sorbed phase in Figure 2, while it predicted more methane in the free gas phase as shown in Figure 3 more than what the experimental data showed.

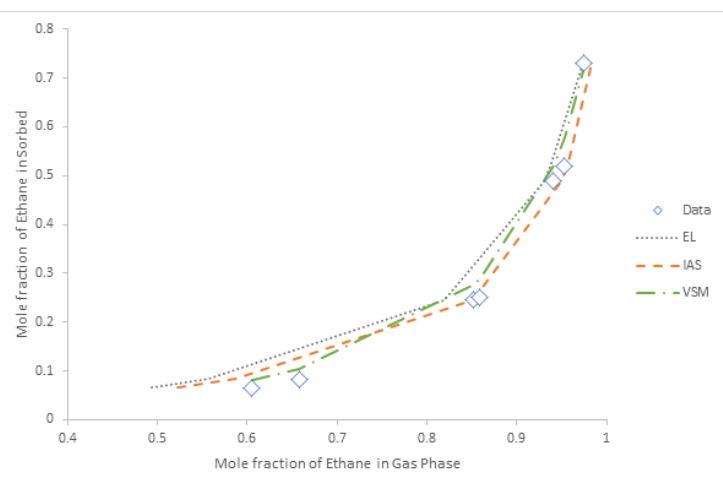

Figure 2 Predicted equilibrium composition diagram showing free gas phase versus the sorbed phase for Ethane

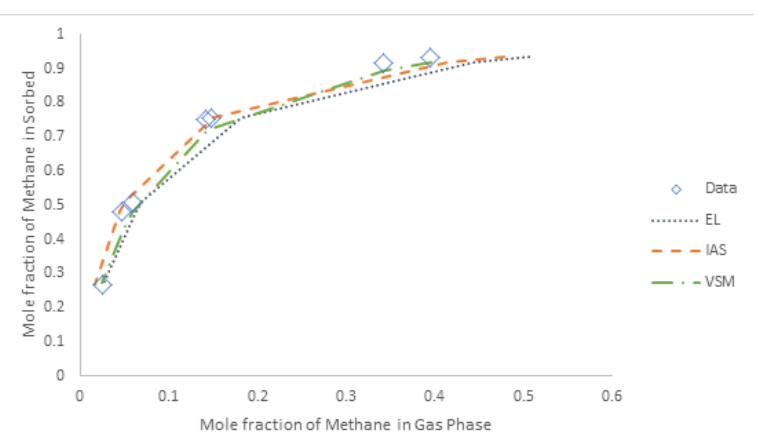

Figure 3 Predicted equilibrium composition diagram showing free gas phase versus the sorbed phase for Methane
For model calculations of EL and IAS, the free gas phase compositions have been inputted and the adsorbed phase mole fraction predicted. However, for VSM, the adsorbed mole fraction was inputted and the free mole gas phase was calculated. To be able to express the relative adsorption of components within an adsorption system, separation factor calculations are useful. ${ }^{45}$ All the models predict a higher selectivity ratio or separation factor for ethane than for methane (see Figure 5). According to Ruthven 1989, the separation factor measures the affinity of the adsorbent for component $i$ relative to the component $j$. This can be expressed as

$\alpha_{i j}=\frac{(x / y)_{i}}{(x / y)_{j}}$

$x_{i}$ and $x_{j}$ refers to adsorbed mole fraction for component 1 and 2 respectively, while $y_{i}$ and $y_{j}$ also refer to free gas mole fraction for component 1 and 2, respectively.

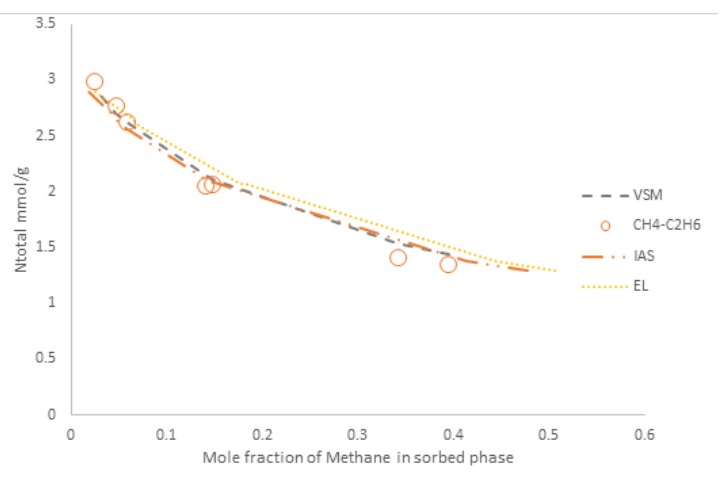

Figure 4 Total volume of mixtures adsorbed at pressures of IOI Kpa

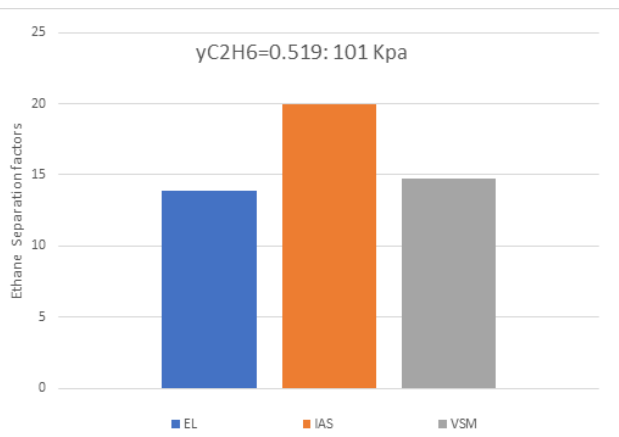

Figure 5 Separation factor calculations for mixtures corresponding to a $0.519-$ mole fraction of Ethane.

The separation factor for the Extended Langmuir (EL) shows a constant value compared to the other models which show variable 
separation factors. This is because, for the EL model, the separation factor is not a function of pressure or composition.

\section{Temperature-dependent Modelling}

Adsorption data obtained from the literature ${ }^{16}$ showed multiple methane adsorption at three different temperatures of $35.4^{\circ} \mathrm{C}, 50.4^{\circ} \mathrm{C}$ and $65.4^{\circ} \mathrm{C}$. Obtaining adsorption data at several temperatures improves the accuracy of the representative adsorption in the reservoir and thereby improves adsorption modelling for the prediction of original gas in place. Both Exponential and Bi-Langmuir models can be used in modelling methane adsorption at several temperatures. With successful application of these temperature-dependent models, numerical simulation of shale gas reservoirs could be improved since the adsorption data obtained would be a better representative of the adsorption in shale. Both temperature dependent models have been used to model the shale gas adsorption data obtained from green river shale. The modelling showed very good prediction at a single temperature and when modelled simultaneously at different temperatures (See Figure 6). Temperature-dependent models can, therefore, be used for single component modelling when adsorption data is provided at a single temperature or at multiple temperatures. Since ARE was found to be best in single component modelling, it has been used as the error function for the temperature dependent modelling. Comparing the performance of Exponential and BiLangmuir models in modelling the adsorption data of Green River shale, the Exponential model provided ARE of 3.64 compared with Bi-Langmuir of 4.51 (See Table 7).

Table 7 MAPE of temperature dependent models in Green River Shale

\begin{tabular}{|c|c|c|c|c|}
\hline \multirow[b]{2}{*}{ Sample } & \multicolumn{4}{|c|}{ Absolute Relative error (ARE) } \\
\hline & Reference & Bi-Langmuir & Exponential & $\begin{array}{l}\text { No. of Data } \\
\text { Points }\end{array}$ \\
\hline Green River Shale & Zhang et al., 2012 & 4.51 & 3.64 & 33 \\
\hline
\end{tabular}

A useful feature of temperature-dependent models is the ability to predict adsorption data at temperatures for which no experimental data exist. This is particularly useful when adsorption data is needed at high temperatures outside the laboratory setup. The models can, therefore, be used to obtain adsorption data at extrapolated temperatures. In order to evaluate the prediction of both Exponential model and BiLangmuir model at an extrapolated temperature, adsorption data at $35.4^{\circ} \mathrm{C}$ and $50.4^{\circ} \mathrm{C}$ has been used for the establishment and calibration of the models and experimental data at $65.4^{\circ} \mathrm{C}$ has been used for validation. Both models predicted differently when extrapolated to $65.4^{\circ} \mathrm{C}$ (See Figure 7). Exponential model seemed to have predicted

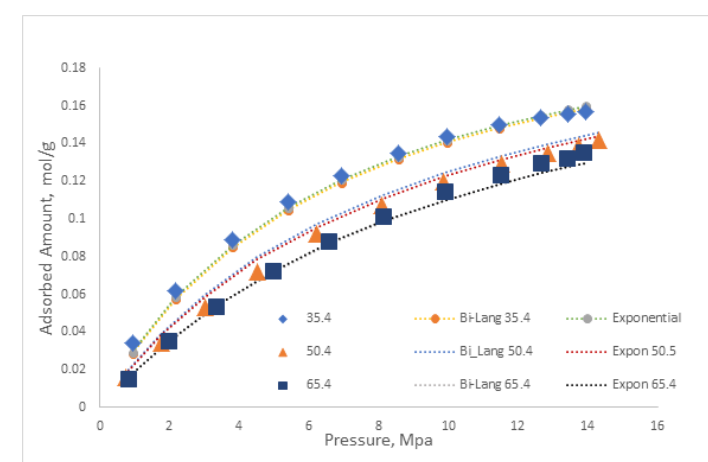

Figure 6 Prediction of methane adsorption at multiple temperatures simultaneously

\section{Conclusion}

This study has analysed the different adsorption models used in the prediction of methane adsorption in shale gas reservoirs by grouping them under single, multi-component and temperature dependent adsorption models. The choice of adsorption model and error function selected has been based on a more statistically robust method of finding the sum of the normalised errors (SNE). Results obtained for single component modelling showed that ARE was the most dominant error function that gave the best fit to the adsorption data in New Albany shale. 6 out of the 12 results of SNE calculations showed more accurately when compared with the Bi-Langmuir model at the extrapolated temperature of $65.4^{\circ} \mathrm{C}$. This implies that for Green River shale, Exponential model should be used in modelling gas adsorption in numerical simulations where thermal strategies are considered. (See Table S12 for model parameters). The predicted results clearly show that caution must be exercised when using temperature-dependent models for extrapolation purposes. This has serious implications when used in numerical simulations since different recoveries might be obtained depending on the adsorption model used. It is therefore important to do a rigorous validation before extrapolation to obtain accurate results.

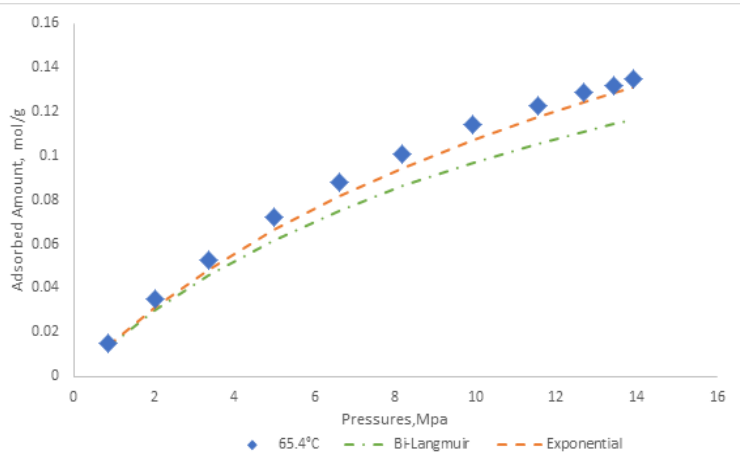

Figure 7 Prediction of gas adsorption at extrapolated temperature of $65.4^{\circ} \mathrm{C}$ in Green River Shale (Zhang et al.,20I2)

minimum SNE for ARE error function. Overall, the Langmuir model gave the most accurate predictions for single component modelling compared with other models for New Albany Shale. In Binary mixture studies, VSM proved to give accurate results for Methane and Ethane adsorption on Activated carbon and fitted the data more appropriately compared with IAS and EL models. The study also showed that the application of temperature-dependent adsorption models offers the flexibility of accounting for adsorption at multiple temperatures including temperatures outside laboratory conditions. Furthermore, the Exponential model provided the most accurate results when modelling methane adsorption of green river shale formation at 
multiple temperatures. Caution must be exercised in the use of the models for extrapolation to higher temperatures and further validation may be necessary when predicting the gas adsorption values at those temperatures.

\section{Nomenclature}

$A^{\prime}=$ specific surface area of the adsorbent.

$a_{i}=$ partial molar surface area of $\mathrm{i}$

$b=$ langmuir constant

$b_{1}=$ henry's law constant for component one

$C=$ constant related to the net heat of adsorption

$D_{T}=$ reduction coefficient related to temperature increase

$E=$ energy of adsorption

$E_{1}=$ adsorption energy

$f_{1}=$ fraction of adsorption site

$i, j$ = gas components

$k_{1,2}=$ adsorption equilibrium constant

$n=$ maximum number of adsorption layers

$n_{a}(p)=$ pure component isotherm

$n_{m}^{s}=$ total number of moles of mixture in surphase phase

$n_{i}^{s, \infty}=$ maximum number of $\mathrm{i}$ in surface phase

$n_{m}^{s, \infty}=$ maximum number of moles of $\mathrm{i}$ in surface phase

$n_{1}^{\infty}=$ maximum number of moles of $\mathrm{i}$ in surface phase

$N_{a d s}=$ amount of adsorbed gas per unit volume adsorbent

$N_{m}$ = amount of adsorbed gas at monolayer coverage

$N$ = number of data points for the isotherm

$P=$ gas pressure

$P_{O}=$ the saturation pressure of the gas

$P_{L}=$ langmuir pressure corresponding to one half of the langmuir volume

$P_{L i}=$ langmuir pressure constant for pure component i , (psia)

$P_{g}=$ gas phase pressure, (psia)

$p_{i}^{o}=$ vapour pressure of the pure component

$P_{i}^{o}=$ standard state pressure of pure component $\mathrm{i}$ in gas phase (psia)

$r=$ number of parameters in adsorption model

$R=$ universal gas constant

$T$ = temperature of adsorption system

$V=$ the volume of adsorbed gas

$V_{L}=$ langmuir volume or maximum gas adsorption at infinite pressure

$V_{m}=$ maximum adsorption gas volume

$V_{L i}=$ langmuir volume constant for pure component $\mathrm{i}$, (scf/ton)

$V_{s}=$ theoretical maximum adsorption capacity
$V_{i}=$ adsorbed volume of component i, (scf/ton)

$W=$ volume adsorbed volume

$W_{o}=$ micro pore volume

$x_{i}=$ sorbed phase gas mole fraction

$X_{\text {ical }}=$ calculated adsorbed concentration,

$X_{i \exp }=$ experimental adsorption data

$x^{a}{ }^{a}=$ molar composition of component $\mathrm{i}$ in adsorbed phase (fraction)

$y_{i}=$ gas phase composition of component $\mathrm{i}$ (fraction)

$\beta=$ affinity of the sorbent for the gas

$\pi=$ spreading pressure

$\varphi_{i}=$ fugacity coefficient of pure component $\mathrm{i}$ in gas phase, (dimensionless)

$\varphi_{i}{ }^{\circ}=$ fugacity coeffeient of pure component $i$ in gas phase at standard condition (dimensionless)

$\theta=$ fractional coverage

$\Lambda_{v 1}, \Lambda_{1 v}=$ wilsons parameters for interation between vacancy and adsorbate

$\phi_{i}=$ fugacity coefficient of $\mathrm{i}$ in bulk gas mixture

$\gamma_{i}^{s}=$ activity coeeficient of $\mathrm{i}$ in adsorbed phase vacancy solution

Reduced Kirchoff equation for calculation of saturation pressure:

$P_{o}=P_{c} \exp \left[\frac{T_{n b p}}{T_{c}}\left(\frac{\ln P_{c}}{1-T_{n b p} / T_{c}}\right)\left(1-\frac{T_{c}}{T}\right)\right]$

$P_{c}=$ critical pressure

$T_{n b p}=$ temperature at normal boiling point

$T_{c}=$ critical temperature

\section{References}

1. Curtis JB. Fractured shale-gas systems. AAPG Bull. 2002;86(11):19211938.

2. Ahmadpour A, Wang K, Do DD. Comparison of models on the prediction of binary equilibrium data of activated carbons. AIChE J. 1998;44(3):740752.

3. Bazan RE, Bastos-Neto M, Staudt R, Papp H, Azevedo DCS, Cavalcante Jr CL. Adsorption equilibria of natural gas components on activated carbon: pure and mixed gas isotherms. Adsorpt Sci Technol. 2008;26(5):323-332.

4. Charoensuppanimit P, Mohammad SA, Gasem KA. Measurements and modeling of gas adsorption on shales. Energy Fuels. 2016;30(3):23092319 .

5. 5. Chen L, Jiang Z, Liu K, et al. Application of Langmuir and DubininRadushkevich models to estimate methane sorption capacity on two shale samples from the Upper Triassic Chang 7 Member in the southeastern Ordos Basin, China. Energy Explor Exploit. 2017;35 
6. Clarkson CR, Haghshenas B. Modeling of supercritical fluid adsorption on organic-rich shales and coal. In: SPE Unconventional Resources Conference-USA. Society of Petroleum Engineers; 2013.

7. Guo W, Hu Z, Zhang X, Yu R, Wang L. Shale gas adsorption and desorption characteristics and its effects on shale permeability. Energy Explor Exploit. 2017;35(4):463-481.

8. Sandoval DR, Yan W, Michelsen ML, Stenby EH. Modeling of shale gas adsorption and its influence on phase equilibrium. Ind Eng Chem Res. 2017;57(17):5736-5747.

9. Tang X, Ripepi N, Luxbacher K, Pitcher E. Adsorption models for methane in shales: Review, comparison, and application. Energy Fuels. 2017;31(10):10787-10801

10. Wang Y, Tsotsis TT, Jessen K. Competitive sorption of methane/ethane mixtures on shale: measurements and modeling. Ind Eng Chem Res. 2015;54(48):12187-12195.

11. Yu W, Sepehrnoori K, Patzek TW. Modeling gas adsorption in Marcellus shale with Langmuir and bet isotherms. SPE J. 2016;21(02):589-600.

12. Ross DJ, Bustin RM. Shale gas potential of the lower Jurassic Gordondale member, northeastern British Columbia, Canada. Bull Can Pet Geol. 2007;55(1):51-75.

13. Lu X-C, Li F-C, Watson AT. Adsorption studies of natural gas storage in Devonian shales. SPE Form Eval. 1995;10(02):109-113.

14. Ross DJ, Bustin RM. The importance of shale composition and pore structure upon gas storage potential of shale gas reservoirs. Mar Pet Geol. 2009;26(6):916-927.

15. Chalmers GR, Bustin RM. Lower Cretaceous gas shales in northeastern British Columbia, Part I: geological controls on methane sorption capacity. Bull Can Pet Geol. 2008;56(1):1-21.

16. Zhang T, Ellis GS, Ruppel SC, Milliken K, Yang R. Effect of organicmatter type and thermal maturity on methane adsorption in shale-gas systems. Org Geochem. 2012;47:120-131.

17. Raut U, Famá M, Teolis BD, Baragiola RA. Characterization of porosity in vapor-deposited amorphous solid water from methane adsorption. $J$ Chem Phys. 2007;127(20):204713.

18. Wei G, Xiong W, Shusheng G, Zhiming H, Honglin L, Rongze Y. Impact of temperature on the isothermal adsorption/desorption of shale gas. Pet Explor Dev. 2013;40(4):514-519.

19. Hildenbrand A, Krooss BM, Busch A, Gaschnitz R. Evolution of methane sorption capacity of coal seams as a function of burial history-a case study from the Campine Basin, NE Belgium. Int J Coal Geol. 2006;66(3):179-203.

20. Chareonsuppanimit P, Mohammad SA, Robinson Jr RL, Gasem KA. High-pressure adsorption of gases on shales: Measurements and modeling. Int J Coal Geol. 2012;95:34-46.

21. Fianu J, Gholinezhad J, Hassan M. Comparison of temperature-dependent gas adsorption models and their application to shale gas reservoirs. Energy Fuels. 2018;32(4):4763-4771.

22. Yang F, Xie C, Xu S, Ning Z, Krooss BM. Supercritical methane sorption on organic-rich shales over a wide temperature range. Energy Fuels. 2017;31(12):13427-13438

23. Sreńscek-Nazzal J, Narkiewicz U, Morawski AW, Wróbel RJ, Michalkiewicz B. Comparison of optimized isotherm models and error functions for carbon dioxide adsorption on activated carbon. J Chem Eng Data. 2015;60(11):3148-3158.

24. Ho YS, Porter JF, McKay G. Equilibrium isotherm studies for the sorption of divalent metal ions onto peat: copper, nickel and lead single component systems. Water Air Soil Pollut. 2002;141(1-4):1-33.
25. Allen SJ, Gan Q, Matthews R, Johnson PA. Comparison of optimised isotherm models for basic dye adsorption by kudzu. Bioresour Technol. 2003;88(2):143-152.

26. Kumar KV, Porkodi K. Mass transfer, kinetics and equilibrium studies for the biosorption of methylene blue using Paspalum notatum. J Hazard Mater. 2007;146(1-2):214-226.

27. Brunauer S, Emmett PH, Teller E. Adsorption of gases in multimolecular layers. J Am Chem Soc. 1938;60(2):309-319.

28. Do DD. Equilibria and Kinetics. Imperial College Press, London; 1998.

29. Kapoor A, Ritter JA, Yang RT. An extended Langmuir model for adsorption of gas mixtures on heterogeneous surfaces. Langmuir. 1990;6(3):660-664.

30. Suwanayuen S, Danner RP. Vacancy solution theory of adsorption from gas mixtures. AIChE J. 1980;26(1):76-83.

31. Kaul BK. Correlation and prediction of adsorption isotherm data for pure and mixed gases. Ind Eng Chem Process Des Dev. 1984;23(4):711-716.

32. Yang RT. Gas Separation by Adsorption Processes. ButterworthHeinemann; 2013.

33. Markham EC, Benton AF. The adsorption of gas mixtures by silica. J Am Chem Soc. 1931;53(2):497-507.

34. Arri LE, Yee D, Morgan WD, Jeansonne MW. Modeling coalbed methane production with binary gas sorption. In: SPE Rocky Mountain Regional Meeting. Society of Petroleum Engineers; 1992.

35. Myers AL, Prausnitz JM. Thermodynamics of mixed-gas adsorption. AIChE J. 1965;11(1):121-127.

36. Ruthven DM. Principles of Adsorption and Adsorption Processes. John Wiley \& Sons; 1984.

37. Ye Z, Chen D, Pan Z, Zhang G, Xia Y, Ding X. An improved Langmuir model for evaluating methane adsorption capacity in shale under various pressures and temperatures. J Nat Gas Sci Eng. 2016;31:658-680.

38. Clarkson CR. Application of a new multicomponent gas adsorption model to coal gas adsorption systems. SPE J. 2003;8(03):236-251.

39. Foo KY, Hameed BH. Insights into the modeling of adsorption isotherm systems. Chem Eng J. 2010;156(1):2-10.

40. Porter JF, McKay G, Choy KH. The prediction of sorption from a binary mixture of acidic dyes using single-and mixed-isotherm variants of the ideal adsorbed solute theory. Chem Eng Sci. 1999;54(24):5863-5885.

41. Valenzuela DP, Myers AL. Adsorption Equilibrium Data Handbook. Prentice Hall; 1989.

42. Szepesy L, Illés V. Adsorption of Gases and Gas Mixtures, III. Investigation of the Adsorption Equilibria of Binary Gas Mixtures. Acta Chim Hung Tomus. 1963;35:245-254.

43. Fitzgerald JE, Robinson RL, Gasem KA. Modeling high-pressure adsorption of gas mixtures on activated carbon and coal using a simplified local-density model. Langmuir. 2006;22(23):9610-9618.

44. Ren W, Tian S, Li G, Sheng M, Yang R. Modeling of mixed-gas adsorption on shale using hPC-SAFT-MPTA. Fuel. 2017;210:535-544.

45. Hartman RC, Ambrose RJ, Akkutlu IY, Clarkson CR. Shale gas-in-place calculations part II-multicomponent gas adsorption effects. In: North American Unconventional Gas Conference and Exhibition. Society of Petroleum Engineers; 2011. 